\title{
1 Finding a common economic pathway
}

Big history considers all traces left that are relevant to the writing of history, whether in middens or within the cells of humans. A trace is anything that encodes some sort of information about the past. There has been a massive extension in what encodes information about the past. Today the evidence for early human history includes a wide range of objects, including artefacts, fossils, vegetable remains, behavioural patterns, potsherds, rocks, isotopes, phonemes and DNA. One commentator likens DNA to a parchment and behavioural traits to archives. (Smail 2007: 48)

In writing a global history it is necessary to identify the patterns characterising that history. Without such an identification the history remains banal, repetitive and without a means of understanding the direction it has taken. There is a danger of the intrusion of value judgements about the experience of various civilisations, what they did and did not do. Historians often talk of golden and silver ages or even of dark ages. Identifying them involves a subjective judgement. It is helpful to try to develop a history without any presuppositions about whether one civilisation is good and another bad. In a powerful sense, the economic base of a society is value neutral.

The first task of this book is to establish a suitable framework for analysing the changes which have marked human history; that is, to identify the major dynamics of such change, and to unravel causes and consequences. Inevitably this means periodising that history, dividing the history into different phases. Any such division into discrete periods provides a structure for the book, an appropriate division into sections and chapters. The division articulates a major task of the narrative as an explanation of the movement from one phase to another. This chapter considers alternative ways of organising such a history, notably the criteria by which a history of the global economy could be divided into separate value-free phases. At the start it aims to keep the classification as simple as possible.

The pathway traced by the global economy is characterised by phases through which all human groups have already passed, or will do in the future. It is impossible to write specific histories without having a clear conception of an overall story into which local stories fit. It is a challenge to recount such stories in an intelligible manner, highlighting the enabling and disabling conditions and the key causal mechanisms moving an economy along the common pathway. The author opts for a periodisation based on the changing nature of the predominant economic activities which have met human needs and satisfied their wants. There are four types of such activity, differing markedly in nature: foraging, agriculture, industry and services. The activities are associated with particular methods of production and distinctive patterns of consumption. This is to jump the gun; we need to start from the beginning, justifying the periodisation chosen.

The most striking features of any global historical narrative were as follows. First, there was the emergence of Homo sapiens, including the outcompeting of other hominids and the spread of Homo sapiens across the world. A major accomplishment 
of humans was the peopling of the world in a period of less than 100000 years after the departure from Africa. No potential barrier succeeded in preventing this, whether arid deserts, barren icy wastes, or wide open and nearly empty oceans. Secondly, there were multiple introductions of agriculture, independently achieved in different places, and a subsequent diffusion both of farmers, with their livestock, plants and tools, and of the idea of agriculture from these initial centres. Thirdly, there was the movement from forager band to village, towns and cities, then to empire and finally to nation state, including repeated urban revolutions, that is, the appearance of cities, usually at the core of agrarian civilisations and increasingly the venue of innovation. Fourthly, there occurred the extension of informational and commercial networks in a process usually referred to as globalisation. Fifthly, there came the modern economy, with the advent of industrialisation, often within the factory system - after the so-called Industrial Revolution - and then the service economy - after what we can label the Service Revolution.

This sequence of events and the movement from one to another represents a common experience. The common pathway includes such dramatic transitions as the agricultural and industrial revolutions. It is not difficult to recognize such turning points, however hidden they may be in any macro quantitative data. Beginning each economic phase is a transition, characterised by a surge in innovativeness, prompted by the implementation of a number of technologies with transformative consequences, often labelled general-purpose technologies. Over the passage of history these transitions come faster and faster. All represent major steps towards an increasing complexity of technology and organisation.

An economist conventionally divides the inputs to economic production into three factors of production: land (resources), labour and capital. Land and resources are in a strict sense fixed in supply; labour grows with population, and capital expands with savings and investment decisions. Through the relevant economic phases, the relative importance of factor inputs changes. The ratio of employment of people (labour) to land changes. Over history the size of population and the labour force has increased enormously, while the amount of land (resources) is finite. This implies that the ratio of people to land has risen dramatically, a phenomenon driving other economic and social, even political, change. Population often presses on the supply of land and its carrying capacity in producing food. Demographic change is an important driver of historical change. The ratio of capital to people has also grown, but does not change in such a volatile manner, at least not until the modern era and the introduction of the industrial factory and the machinery housed in it. $^{1}$

Innovation tends to use intensively those inputs which are relatively abundant at the time, or promise to become significantly more abundant in the near future. An important focus of interest is a changing bias in the use of the factors, imparted by the technologies characterising the different phases. In the agricultural phase, labour is substituted for land, in the industrial phase, machines for labour, causing rises in the labour to land and the capital to labour ratios. Analysis of historical change has as a significant theme the changing nature of the relevant transformative technologies and the way in which the technologies respond to, and use in changing mixes, the available factors of production. The structure of the economy changes to reflect the dominant technologies and their use of the different factors of production. 


\section{A history of the global economy}

This chapter focuses on the nature of the common economic pathway through which all societies pass. It begins, in the next section, by arguing the general need for a periodisation of history. The subsequent section focuses on the significant historical changes in the structure of an economy which underpin the division into different phases. It identifies the nature of the economic pathway. The chapter concludes by dating the relevant economic phases, pinpointing the time when the relevant thresholds were crossed and new phases entered, an experience common to all societies, even if the exact timing differs.

\section{INTERPRETING THE GLOBAL HISTORICAL EXPERIENCE}

Smart, educated people reflect on the problems facing them, and if they face similar issues they will come up with similar ranges of responses, regardless of where and when they live.

(Morris 2011: 420)

We better understand historical change by dividing history into meaningful segments, separate economic phases sufficiently distinguished from each other by defining characteristics. ${ }^{2}$ There is a sequence of structural changes by which we can identify the material aspects of the story. There is a simple and commonly used classification of the economy into three sectors: the primary - chiefly agriculture but also fishing, forestry and mining; the secondary - industry, commonly and mistakenly called manufacturing; and the tertiary - services. Before the rise of these sectors, humans were foragers, hunting and gathering. Economic history unfolds through a sequence of phases in which each economic sector in turn predominates. Although all relevant activities exist in each of the phases, the differentiating magnitudes are the dimensions of output and employment in the different sectors. A phase is defined by the dominance of one sector. All societies follow an economic pathway tracing the predominance of one sector after another, but movement occurs at different speeds.

Humans follow the pathway by deliberate choice; they see advantage in so doing, motivated by the usual economic incentives and a growing acquisitiveness and inquisitiveness. They desire consumer goods of increasing sophistication. Their suppliers deliberately emulate best practice in producing the relevant goods, increasingly driven by competition to do so, and to act to best meet an expanding demand, which starts with that for subsistence goods and luxury items for a narrow ruling group, and finishes nowadays with a much larger consumer society in which all share a wide range of consumer goods in an age of mass production and mass consumption.

There are four different phases linked to the predominance in turn of foraging, agriculture, industry and services, and two sub-phases, subordinate to the main phases, the urban and commercial, occurring respectively at the beginning and towards the end of the agricultural phase, important enough to merit a separate treatment since they powerfully promote movement into and through the agricultural phase. The sub-phases involve the separation of production and consumption as a result of an exchange of services and goods between town and country and, later, between different regions and countries. The sub-phases are catalytic, promotive of the movement of any society 
along the general economic pathway. ${ }^{3}$ They merit the commitment of two separate sections of the book to their historical role.

There is a need for a holistic approach in explaining the impetus to innovation, considering how all the different facets interact to influence progress along the economic pathway. ${ }^{4}$ Many facets act in combination to propel such change - whether economic or political, demographic or technological, social or religious, cultural or genetic - and all have their role. Together these facets reflect critical themes: the evolution of an awakening human intellect and a sharpening cognition; an increasing intensity of communication and cooperation; and the diffusion of existing best-practice technology through expanding communication networks.

Human innovativeness manifests itself not just in economic and technological change, but in changing social and political organisation and the emergence of new intellectual paradigms which assist humans in understanding the world around them. Increasingly, an improved intellectual understanding underpins innovation, sometimes based on extensive empirical experience, at other times on a more comprehensive and systematic knowledge, denoted as science; increasingly the latter in the modern world.

The emphasis in this book is on the economic. ${ }^{5}$ Economists often equate economic development with the evolution of markets, stressing the enormous influence of an expanding network of exchange and, resulting from this, a more pronounced division of labour and specialisation. There is throughout history the appearance and growth of various markets, and no doubt that, despite frequent failures, the role of the market is important in promoting innovation. ${ }^{6}$ Economies of both scale and scope result from expansion of markets. The spread of the market is an aspect of any economic change, but it is not the main driving force; rather the consequence of human creative innovativeness than a cause.

Others have focused on the technological base, stressing three key areas of innovation: accelerating and widening communication between humans; use of different materials; and tapping new energy sources. The technologies determining the nature of interpersonal communication have a special role to play in human history. Such improvements occur at key historical moments. These technologies are powerful enabling devices for movement along an economic pathway, stimulating imitation and innovation, whether as the introduction of language, of writing, of printing, or of the telegraph and other electronic media. The postal service was an innovation in the improvement of communications (Graeber 2015; Grayling 2016), and much underrated. Such changes are often linked with, and reinforced by, improvements in transportation.

There are also periods of acceleration in the dominant material base of economic life. Reflecting this is the traditional classification made for early humans, from Old Stone Age (palaeolithic), to Middle Stone Age (mesolithic) and New Stone Age (neolithic), then to the Bronze Age and the Iron Age, even into early, middle and late periods in each of these ages. Earlier tool cultures are distinguished and named (Christian 2004: 161), just as pottery styles are often seen as characterising and differentiating certain civilisations (Ostolaza 2009). There is a strong temptation to do this since the obvious record of early societies is material, but the distinctions are often artificial and regionally based. Also, accounts which stress a changing source of the energy that powers the processing of materials, from human and then animal sources to wind and 


\section{A history of the global economy}

water power, and then to fossil fuels, are currently popular. Innovation in the technologies of production has required the application of ever more energy, and the tapping of a sequence of new sources. Both the sourcing and the exploitation of new energy sources have been critical to phase entry.

One problem in the relevant literature is the tendency to place intellectual revolutions alongside economic revolutions, giving them an equal standing (Harari 2014). It is better to trace a consistent theme running through historical change. The preferred procedure in this book is to focus on the underlying economic activity, classifying the economic phases by their defining activity, the dominant method of producing and consuming the products and services needed and wanted by humans.

A phase is entered through the adoption of innovations transforming the basic economic activities. ${ }^{7}$ These transformative innovations make possible the domination of particular economic activities. We should not ignore the role of urban and commercial transformations in this: first, the appearance of complex conurbations at the heart of agrarian civilisations, the cities themselves made possible by major innovations, and secondly, the appearance of commercial interactions, trade often enabled by significant improvements in communication, transport and finance. The identification of the phases and the technologies which characterise them makes possible a periodisation of the narrative, dividing it into meaningful periods of time, described in this book as phases.

\section{THE CHANGING STRUCTURE OF AN ECONOMY}

An era does not just create technology. Technology creates the era. And so the history of technology is not just the chronicle of individual discoveries and individual technologies: the printing press, the steam engine, the Bessemer process, radio, the computer. It is also the chronicle of epochs - whole periods - that are defined by how their purposes are put together. (Arthur 2009: 75)

During the agricultural phase the primary sector dominates, during the industrial phase the secondary, and during the service phase the tertiary. There has always been some manufacturing in every economy, even before the industrial age, and some services were necessary to both an agrarian and an industrial economy. What is relevant is the dominance of each of the sectors during the relevant phases, their central role in the overall economy, whether measured by share of employment or by proportional contribution to gross domestic output. ${ }^{8}$

The three sectors - primary, secondary and tertiary - differ first, according to the mix of inputs of the factors of production required during the relevant phase, and secondly, according to the type of consumer demand they satisfy. ${ }^{9}$ Both price and income influence patterns of supply and demand. New technologies introduce new products and new processes, often reducing price dramatically. However, as incomes rise, the pattern of consumption changes. The consumption of an agricultural peasant differs enormously from that of an industrial worker and more from that of a self-employed information technology consultant.

While the following analysis focuses more on the supply side of the economy, on the nature of the different inputs into the productive process, the other side of the economic 
scissors, the demand side, is equally important. As average income rises, the demand for the products of the different sectors changes in a systematic way. There is a limit to the growth of consumption of the different consumer goods, agricultural or industrial. At particular moments in the movement along the economic pathway, the nature and level of demand are sensitive to reductions in the price of the products of different sectors, that is, to supply-side variations. It is worthwhile, certainly profitable, to introduce new general-purpose technologies which cut costs and price. An innovation may raise the quality of the relevant goods. Real prices, reflecting quality improvements, can fall quickly and significantly during such transitions.

We can dwell for the moment on the nature of the different sectors. In a preliminary phase, the foraging phase, the division into sectors is irrelevant, since there existed no distinctive economic activities and no markets, as we would understand them. Yet both gathering and hunting may require significant knowledge of ecological systems and habitats. Material subsistence involved a simple and largely direct interaction between humans and their environment, although hunting involved a greater organisational input than did gathering. The link between a foraging Homo sapiens and the means of their survival is usually direct. Food is gathered and consumed almost immediately. The phase may start with an opportunist gathering regime, but finish with a more controlled foraging and an increasing focus on hunting and meat eating. Even in the foraging phase there is an expression of creative innovativeness.

During this phase there was the first application of the general-purpose principles which determine whether, and how, basic human needs and wants are satisfied. There was a tentative start to important innovations: the processing of a range of available natural resources, using techniques such as cutting and grinding, cooking, firing (pyro-technology) and therefore heating, some storing of relevant foodstuffs, and making crude clothing, even basic rafts. The activities associated with pottery, textiles and metalworking make their start towards the end of the forager phase. This represents a display of creative imagination.

The primary sector, comprising agriculture and fisheries, but also forestry and mining, initially consists of those parts of the economy which continue to exploit natural resources directly, but increasingly involve some degree of direct human control and a commitment of more labour time to their production. Agriculture, sometimes supplemented, even substituted, by fisheries, is at the core of the primary sector, and involves economic activities in which both plants and animals are manipulated to yield subsistence products through processes devised by humans. After the Agricultural Revolution the primary sector dominates the economy. ${ }^{10}$ Seeds are deliberately planted and harvested, animals domesticated and used as a source for a range of products in a secondary revolution. First, you have an opportunist gathering of particular plants; then the preferred plants are targeted; next you encourage the growth of these plants in various ways; and finally, you domesticate their planting, taking seeds and placing them in prepared ground.

The relevant primary activities comprise a wide range, extending beyond the growing and consumption of staple crops, and include the collection of spices, the production of milk, meat or the raw materials used in textiles, but also mining for desired stones, such as flints, jade or obsidian, even some deep or opencast mining for copper, tin, coal, iron ore or precious metals such a gold or silver, then fur trapping or honey gathering, the 
exploitation of timber or the catching of fish and gathering of shellfish, even whaling. In an agricultural economy there is a direct exploitation of the natural capital found in the physical environment, which includes fertile soil, the fauna and flora themselves some wild, some domesticated - both on land and in the sea, the forests that cover the land, the deposits of minerals, including clay and stone, even the water and the air. Some resources are renewable: trees can be replanted or animals bred, but even in modern agriculture there is a net consumption of natural capital, as the fertility of the soil is used up.

The secondary sector, industry, is characterised by a more significant and extended processing of natural resources, sometimes requiring many vertical layers of such processing. Industrial production is more and more complex, or roundabout, with a considerable processing of raw materials required before the end product is produced. The output of the industrial sector typically bears no resemblance to the natural resources from which it is derived, including as disparate a set of commodities as a biscuit or loaf of bread, a pair of shoes or a plasma television set, a set of Wedgwood crockery or a mobile phone. The phase dominated by industry is initiated by the Industrial Revolution. The emphasis in overall output of a region or country shifts from the primary sector to the processing and assembly of industrial products within the secondary sector.

The output of the secondary sector consists of both consumer and capital goods. Capital goods, especially machines, can be used to produce either more capital goods or more consumer goods. During the industrial phase they are often directed to the former. There is a much-increased application of physical capital, in the form of plant and equipment as well as buildings, notably machinery, and an increased input of energy to work that machinery. The machines replace labour, but require an alternative source of power. This increase in the use of energy is applied in the mechanisation and automation of production, currently in some industries completely replacing labour. The use of robots represents a completion of this phase.

In any sector innovation does not cease, even if the sector is contracting after the transition to a later economic phase. The sectors which decline receive inputs from those on the rise, increasing their productivity, sometimes strikingly. During the industrial phase these inputs consist of equipment, such as tractors or harvesters, and other industrial inputs, such as fertilisers, and during the service phase, human expertise. The term, industrialisation of agriculture, captures this influence. In a modern economy machinery becomes ever more sophisticated, with the replacement of labour by capital in both the extraction and the processing of relevant natural resources. Earth-moving equipment, fish factory ships, an opencast coal mine and oil wells plumbing the depths of the oceans, reflect complex technologies. The productivity of farming or mining has increased enormously, that of fishing and forestry almost as dramatically. The high productivity of agriculture or mining is one reason why the share of employment in these sectors is currently so low.

The tertiary sector is the service sector, in which there is a provision of a utility without a tangible physical product. It may be an input reflecting the expertise of a consultant. It involves significant face-to-face contact and considerable input of human expertise. The use of industrial goods becomes secondary to the provision of a service, such as a book used in the teaching of an educational course, a cyclotron assisting 
research in basic physics, a computer as part of a booking system for an airline, and $\mathrm{X}$-ray machines, magnetic resonance imagers and other scanners for medicine. There is an enormous range of such services, but the danger is to associate such services with activities such as domestic service, retailing or tourism. This sector rests on the input of human capital (knowledge and expertise), with a much higher input of education and training and the commitment of a longer period of time than earlier. It is not unusual for the highly educated to enter the workforce in their late twenties. Research and development is increasingly at the core of the service sector, which is represented as much by an input of 'high technology' as of waiter service. Industrial goods are increasingly delivered within a package of specialised and highly sophisticated services. ${ }^{11}$

The classification of phases is by no means new, being associated with the work of Fourastie, Fisher and Clark (Clark 1957), and revived at discrete intervals. Table 1.1 illustrates the situation as a typical economy moves along the common pathway from phase to phase.

\section{Table 1.1 Typical shares of the workforce in different sectors}

\begin{tabular}{llll}
\hline Phase & Primary & Secondary & Tertiary \\
\hline Agricultural phase & 70 (up to 90) & 20 (and below) & 10 (and below) \\
Industrial phase & 40 & 40 (ranges from 25 to 45) & 20 \\
Service phase & 10 (and below) & 20 (and below) & 70 (up to 85) \\
\hline
\end{tabular}

The important feature in Table 1.1 is the profile of movement in shares from phase to phase. The main figures represent averages, those in brackets observed variations. Most specific variations from the average pathway are marginal and easily explained. ${ }^{12}$ Although all countries travel the same economic pathway, the timing of movement varies.

A pre-modern economy had most labour employed in the primary sector. In the typical pre-industrial society, most of the population was engaged in the primary sector, notably agriculture, employed in producing food - as much as 90 per cent of the overall labour force. Fishing, defined broadly, could register the same level of engagement where there were rich maritime or riverine fishing grounds. The industrial and service sectors were, in this period, small in terms of output and employment, both simply add-ons to agricultural activity and often limited to providing for a ruling elite. For much of history, agricultural producers were peasants consuming a high proportion of what they produced and operating at a low level of productivity, suggesting income levels often close to subsistence level. The state of the harvest typically determined the level of well-being of the population at large and the demand for other products, including industrial goods or services. Around the world there are still economies which consist largely of a primary sector.

There is an underlying forward economic movement which simply reflects the creative innovativeness of Homo sapiens. The potential for movement into any phase unfolds within the previous phase; it is a matter of the appearance of relevant enabling conditions and the removal, or neutralising, of the disabling conditions which had 
previously inhibited economic movement. For example, the processes of urbanisation and commodity exchange accelerated the transition from the agricultural to the industrial phase, by putting in place conditions enabling the expansion of industry, creating a demand for industrial products and making available the inputs needed to support a much raised level of industrial activity.

Only a rise in productivity in the primary sector, and/or an openness to trade with countries having a surplus in that sector, allowed the transition to the industrial phase to proceed significantly. Somewhere there had to be a rise in the size of the surplus, to levels well above the subsistence needs of the producers, such a rise implying the possibility of an increasing degree of economic exchange. The marketing of agricultural surpluses underpinned the spread of the commercial economy, but it did more than this. The rise in agricultural productivity could establish a number of conditions enabling modern economic development: providing the raw materials required as inputs in the production of industrial goods; freeing workers from the primary sector to move and find employment in the secondary sector; generating demand for the products of that sector, both within the primary sector itself, and from those moving out of this sector; and causing savings, in the form of investment funds, to move out of the primary sector to finance investment in physical capital in the secondary sector. Such individual contributions were to some degree mutually exclusive, but an acceleration in the rate of productivity increase can contribute enough to make a real difference. ${ }^{13}$

The inception of what is best called modern economic development saw a relative decline of the primary sector and a rise in the secondary sector. Entry into the modern economy involved a dramatic acceleration in the rate of industrialisation and an increasing location of industry within the factory system, that is, a significant rise in the importance of the secondary sector. In the economies furthest along the economic pathway, the seeds of change were planted as early as the sixteenth century in Europe, earlier in parts of Asia. This often took the form of a proto-industrialisation, comprising a putting-out system, chiefly located within the rural sector, with relatively low levels of productivity. Industrialisation became really significant in the nineteenth century, with innovations indicating the advent of the factory system.

The service phase is the second stage of modern economic development, in which we are currently engaged. At a high level of average income all developed economies become service economies. During this phase the service sector rises in importance, both relatively in terms of output and employment and absolutely in value of output, while the secondary sector enters a period of relative decline. Entry into this phase began in the USA as early as the 1920s and 1930s, but later in other developed countries. The full inception of a service economy was postponed by the shocks occurring in the first half of the twentieth century - two world wars and the Great Depression, slowing the pace of innovation and restricting the rise in income.

It should be re-emphasised that the relative decline of a sector does not mean absolute decline. As with the primary sector during industrialisation, the industrial sector could, in a period of relative decline, continue to display a significant rise in productivity. In a developed economy, there is a tendency for the industrial sector to produce high-technology, high-quality niche goods. The 'Asian miracle', with the rapid industrialisation of a number of Asian economies, accelerated the transition into the service phase in the developed world by making available cheap imports of industrial 
goods, often substituting for industrial goods previously produced in both trading partners. The pattern of production in any country is influenced by its pattern of trade, and the changes described above can be accelerated by the stimulus of rapidly expanding trade.

\section{PERIODISING THE NARRATIVE}

The economy ... exists always in a perpetual openness of change - in perpetual novelty. It exists perpetually in a process of self-creation. It is always unsatisfied.

(Arthur 2009: 199-200)

The changing structure of the economy defines the phases of economic activity characterising economic history - from foraging to agriculture, from agriculture to industry and on to services. The modes of production are very different in each phase, so the economy of a later phase would be unrecognisable to humans living and working in an earlier phase. It is easy for us to recognise the phases visually. The typical images of each phase are well known: a group of hunters attacking a mastodon while their female partners gather vegetable foods; neat fields with golden crops and quietly grazing cattle; cities with closely constructed buildings and a network of roads; merchant ships loaded with cargoes; factories noisy with relentless machinery, belching steam; and a smiling doctor delivering medical advice. These images illustrate the transformative technologies at the centre of the relevant phase. The periodisation adopted reflects the sequence of phases dominated by different types of economic activity. It takes time for them to become dominant.

All civilisations go through the same phases, albeit at differing paces and in their own distinctive ways; some are pioneers, some followers. Variations in the nature and timing of movement through the phases arise as a result of differing resource endowments. It should be borne in mind that there is within any economy a clear overlap between different phases. The divisions created by the author can appear arbitrary for two reasons.

First, among the pioneers there are transitional periods of varying length, protoperiods, during which the enabling conditions for the introduction of the transformative technologies relevant to another phase appear and critical disabling conditions are neutralised. There are preparatory stages, what are called proto-agriculture and protoindustry, as well as preliminary movements, causing a growing concentration of urban population and the early appearance of trade in high-value products, representing a proto-urbanisation or a proto-commercialisation. Patches of new phase activity make their first appearance but do not dominate.

There are significant time gaps between the first introduction of a new technology and its later dominance. It may take time for micro-innovations and other transformative innovations complementing the relevant core technology to be introduced. The first tentative steps in the direction of developing any new technology may bear little resemblance to the technology in its final form. This is a period of evolution rather than revolution, implying that any exact dating is a movable feast. Within the agricultural phase the two sub-phases of urbanisation and commerce, urbanisation early and 
commerce later, are accompanied by the significant but as yet gentle appearance of new methods of production and exchange, notably of industrial and service output. They begin to change the location of production towards urban as against rural location and outside sources of output as against domestic.

Secondly, where entry is independently achieved, it does not occur at the same time in different regions of the world. There are delays in entry, sometimes protracted. The origins of the key ideas behind any innovation may lie outside the pioneer economy, and those ideas may need serious adaptation to fit conditions different from those in the pioneer. When the world becomes connected, the introduction of a transformative innovation in one place exerts pressure for its introduction elsewhere. There is competition pushing forward new technologies and emulation of emerging best practice. Those imitating the new technology adapt and develop it, avoiding the problems of its initial development, but this takes time. Sometimes the technology may be installed in a way that makes it superior to the pioneer models and of a markedly higher productivity than any other variant. From an early date, economies in different phases interact, so any periodisation must take account of the influence of phased entries on the economic activity in late starters.

The typical timetable for each phase is as follows. There is a preliminary period of evolutionary rather than revolutionary change. Clear turning points are the first recorded introduction of the relevant general-purpose technologies in a recognisably developed form; then their attainment of dominance in a local region; followed by their global dominance, after a period of discontinuous introduction, adaptation and imitation; and, finally, the full working out of the implications of the transformative innovation, with the assistance of a multiplying host of new applications.

Some of the new applications, involving a fresh set of micro-inventions, presage the transition into the next economic phase. The transitions into the different economic phases are prompted by the introduction of a set of relevant transformative innovations. Transitions from one phase to another are radical enough to be described as revolutions, for example, the Agricultural Revolution, the Urban Revolution, the Commercial Revolution or the Industrial Revolution. ${ }^{14}$

\section{NOTES}

1. Economists attach great importance to the role that prices play in history, guiding the allocation of resources and the distribution of income. The prices of the relevant outputs and inputs, through their impact on revenue and costs, determine whether any new technology is profitable. Political power arises from the ownership of the dominant means of production, notably land in the agricultural phase and capital in the industrial phase.

2. One commentator (Lieberman 2013) has identified seven significant transitions in the passage of hominins. Humans are marked at each stage by significant evolutionary genetic change, suggesting strongly that 'cultural' change has shaped that changing genetic nature. Five fall before the advent of Homo sapiens. The first transition occupied several million years before the first bipedal hominid appeared, consuming a diet largely of fruit. The second transition was the appearance of the australopiths, consuming a broader range of foods. A more distinctive transition, by Homo erectus some 2 million years ago, was to humans with modern bodies and a brain adequate to support a foraging existence, including hunting. In the next transition, the hominids spread out across the Old World. During the fifth transition, after an alleged 'cultural' or intellectual revolution, Homo sapiens 
spread across the globe. Unsurprisingly the last two transitions correspond to the Agricultural Revolution and the Industrial Revolution.

3. By catalytic is meant promotive of movement along the economic pathway. Urban development encourages both commercial and industrial activities - urban areas are the focus for both activities, and commercial activity encourages industrial activity.

4. A recent big history (Harari 2014) has identified three revolutions: a cognitive revolution between 70000 and 30000 years ago; an agricultural revolution about 10000 years ago; and a scientific revolution about 500 years ago.

5. 'Innovation is simply the accomplishment of the tasks of the economy by other means' (Arthur 2009: 164).

6. The tracing of the history of commerce and its impact on the level of specialisation in economic activity has been analysed well (Findlay and O'Rourke 2007).

7. A neat illustration of an early manifestation of independent innovation is a diagram showing how in the early development of civilisations in Western and Eastern Asia, during a period of 10000 years following the end of the Ice Age, roughly the same things happened in almost the same sequence (Morris 2011: 130).

8. Nowadays the level of economic activity is most frequently measured as gross domestic product (GDP). Gross indicates that the depreciation of capital equipment or buildings is ignored. If it is taken into account, national domestic product (NDP) is being measured. Domestic limits the measure to what is produced in a given region, excluding that outside the region. Including the latter, national replaces domestic; gross national product (GNP) becomes the measure. Product could be replaced by income or expenditure, in an ideal statistical world all three would be equal; gross domestic income (GDI) or gross domestic expenditure (GDE) should be equal to GDP.

9. The divisions are not unambiguous, but this does not undermine the main argument.

10. Fishing involves the use of boats or the construction of weirs or fish traps. Mining involves the extraction of ores, often in underground mines. In forestry activities trees have to be felled and timber processed, often into charcoal, and both honey and wax require collection.

11. A recent study revealed that a typical modern enterprise might reflect in its value, 20 per cent for its buildings and plant, but 80 per cent for the value of its brand name(s). The service of marketing has become important.

12. Some economies were born with a large service sector, notably where European settlers predominated. Australia had 30-40 per cent of its labour force so employed as early as the second half of the nineteenth century (White 1992a: 150-54; Ville and Withers 2014, especially chap. 17, Monica Keneley, 'The service economy'), this percentage being probably similar to that at the time of first settlement. There are particular reasons for this: relatively high income levels; the nature of the relationship with the colonising power; the penal background of the Australian colonies; a sparse population on a large continent, making transport and other services important; and a strong role in the economy for government.

13. The alternative was for the surplus to be squandered in the conspicuous consumption of the ruling elite, a picture typical in the past.

14. The language used to describe economic movement is often hyperbolic - miracle, revolution and take-off come to mind. The implied metaphors influence the way we understand the phenomena being discussed. 